\title{
Helicônia "Golden Torch": Produtividade e qualidade pós-colheita sob diferentes fontes e doses de silício
}

\author{
Ademar da S. Paulino', Abel W. Albuquerque ${ }^{2}$, \\ Gilson Moura Filho² \& Francisco R. da S. Pereira ${ }^{1}$
}

\begin{abstract}
RESUMO
Objetivou-se, neste trabalho, avaliar a produtividade de hastes florais e a qualidade pós-colheita no cultivo de helicônia "Golden Torch" em diferentes fontes e doses de silício. O experimento foi montado em blocos casualizados e disposto em fatorial $3 \times 3$ com quatro repetições utilizando-se as fontes cinza de bagaço da cana-de-açúcar, MB-4 e Rocksil ${ }^{\oplus}$ nas doses 0,400 e $800 \mathrm{~kg} \mathrm{ha}^{-1}$ de $\mathrm{SiO}_{2}$ equivalentes a cada fonte. Os resultados obtidos demonstraram que o número de inflorescências cresceu com a fonte Rocksil ${ }^{\bullet}$ o comprimento de brácteas foi maior com a interação entre cinza e a dose $400 \mathrm{~kg} \mathrm{ha}^{-1}$, as perdas de massa ao oitavo dia pós-colheita foram menores com a interação entre Rocksil $^{\bullet} \mathrm{e}$ a dose $400 \mathrm{~kg} \mathrm{ha}^{-1}$, a queima de brácteas ao oitavo dia pós-colheita apresentou menor valor com a fonte Rocksil $^{\oplus}$ na dose $800 \mathrm{~kg} \mathrm{ha}^{-1}$ enquanto o teor de Si no solo cresceu na profundidade de 0-0,20 m com o aumento da dose de silício; já para as variáveis comprimento de hastes florais, massa de hastes florais no dia da colheita e no oitavo dia após a colheita, teor de silício foliar e no solo na profundidade de 0,20-0,40 m não houve diferença significativa entre os tratamentos pelo teste de agrupamento de médias de Scott-Knott. A adubação com silício aumentou a produtividade e a qualidade pós-colheita, destacando-se a fonte Rocksil $^{\oplus}$ na dose $800 \mathrm{~kg} \mathrm{ha}^{-1}$.
\end{abstract}

Palavras-chave: adubação silicatada, flores tropicais, produção

\section{Heliconia Golden Torch: Productivity and post-harvest quality under different sources and doses of silicon}

\begin{abstract}
The objective of this study was to evaluate productivity and postharvest quality of helicônia "Golden Torch" under different sources and doses of silicon. The experiment was conducted in randomized blocks in $3 \mathrm{x}$ 3 factorial design with four replications, using the sources ash from sugarcane bagasse, MB-4 and Rocksil ${ }^{\odot}$ in doses of 0,400 and $800 \mathrm{~kg} \mathrm{ha}^{-1}$ from each source. The results showed that the number of inflorescences increased with the source Rocksil ${ }^{\circ}$, the length of bracts was higher with interaction between ash and dose of $400 \mathrm{~kg} \mathrm{ha}^{-1}$, the mass loss on the $8^{\text {th }}$ day postharvest was lower with the interaction between Rocksil $^{\circ}$ and dose of $400 \mathrm{~kg} \mathrm{ha}^{-1}$, the burning of bracts on the $8^{\text {th }}$ day post-harvest was lowest with source Rocksil $^{\odot}$ under the dose of $800 \mathrm{~kg} \mathrm{ha}^{-1}$ and $\mathrm{Si}$ content in the soil in the depth of 0-0.20 m increased with increasing dose of silicon. As for the variables length of flower stalks and mass of flower stalks on the day of harvest and on the $8^{\text {th }}$ day after harvest, content of silicon in leaf and in soil in the depth of $0.20-0.40 \mathrm{~m}$ there was no significant difference between treatments by grouping test of Scott-Knott. The silicon fertilization increased production and post-harvest quality, especially the source Rocksil ${ }^{\bullet}$ in the dose of $800 \mathrm{~kg} \mathrm{ha}^{-1}$.
\end{abstract}

Key words: silicon fertilization, tropical flowers, production

\footnotetext{
1 Instituto Federal de Alagoas, Campus Satuba, Rua Dezessete de Agosto, s/n, Centro, CEP 57120-000, Satuba, AL. Fone: (82) 3266-1020. E-mail: demadaonca@yahoo.com.br; pereirafrs@hotmail.com

${ }^{2}$ CECA/Universidade Federal de Alagoas, Campus Delza Gitaí, Rodovia BR 104 Norte Km 85, CEP 57100-000, Rio Largo, AL. Fone: (82) $3261-2221$. E-mail: awa.albuquerque@hotmail.com; gilson.moura@fapeal.br
} 


\section{INTRODUÇÃO}

A produção de flores tropicais de corte é uma atividade de destaque no "agrobusiness" e alternativa de investimento tanto para os produtores que se utilizam de altas tecnologias como para os extrativistas da região amazônica que trabalham com a exploração sustentável da floresta (Arruda et al., 2008).

Por serem produzidas em regiões de temperaturas mais elevadas, as flores tropicais vêm ganhando espaço, a exemplo das flores de clima temperado que antes, eram importadas de outras regiões de clima mais ameno e atualmente têm maior produção local. Neste cenário, a helicônia "Golden Torch" (Heliconia psittacorumx Heliconias pathocircinata) tem-se mostrado uma planta promissora para a produção de flores de corte do gênero Heliconia, sobretudo em virtude de apresentar características como beleza e rusticidade, buscadas pelos compradores (Costa et al., 2007).

O silício é um dos elementos mais abundantes da crosta terrestre, presente na maioria nos solos cultiváveis porém não se encontra prontamente disponível. Para isto é necessário que as rochas silicatadas sejam extraídas, trituradas e moídas para aumentar sua superfície de contato, solubilidade e disponibilidade (Oliveira et al., 2007; Ramos et al., 2008).

As fontes de silício são representadas, em sua grande maioria, por rochas ricas neste elemento e, de acordo com a indústria que as beneficiam, recebem nomenclaturas que as identificam no mercado como MB-4 - melhorador de solos formado por dois tipos de rocha: a biotitaxisto com serpentinito - e o Rocksil ${ }^{\circledR}$ - fertilizante oriundo de argilas silicatadas (Brancaglione et al., 2009). Mas ainda existem outros fornecedores de silício que não têm sua origem direta das rochas, como a cinza do bagaço da cana-de-açúcar, produto gerado da queima do bagaço (Cordeiro et al., 2009).

A utilização como fertilizante tem apresentado resultados positivos como resistência ao estresse hídrico, aumento da taxa fotossintética e diminuição do ataque de pragas, principalmente no cultivo de monocotiledôneas, sendo absorvido e acumulado em folhas de bananeiras que pertencem à mesma ordem das helicônias, a zingiberales, além dos benefícios supracitados alguns autores ressaltam que a adubação com silício pode aumentar a produtividade de certas culturas devido ao aumento da resistência ao acamamento, ao estresse hídrico e à desidratação após a colheita (Oliveira et al., 2007; Buck et al., 2008; Feitosa et al., 2010).

Para Santos (2006) o uso de fontes de silício como o silicato de sódio em Heliconia Golden Torch promoveu maior produtividade e menor queima das brácteas pós-colheita. $\mathrm{O}$ autor verificou, utilizando doses de silício entre 0 e $1200 \mathrm{~kg} \mathrm{ha}^{-1}$ com as fontes cimento, silicato de cálcio e silicato de sódio em helicônia "Golden Torch" diferença nos aspectos produtivos e de pós-colheita entre as doses e fontes utilizadas.
Objetivou-se, neste trabalho, avaliar a produtividade, a qualidade pós-colheita e os teores de silício foliar no solo no cultivo de helicônia "Golden Torch"sob diferentes fontes e doses de silício.

\section{Material e Métodos}

O experimento foi conduzido no período de maio de 2010 a maio de 2011, em condições de campo, numa área de terras pertencentes ao Instituto Federal de Alagoas - Campus Satuba, no município de Satuba, AL. A área experimental está localizada a $9^{\circ} 33^{\prime} \mathrm{S}, 35^{\circ} 49^{\prime} \mathrm{W}$ e $10 \mathrm{~m}$ de altitude, distante $15 \mathrm{~km}$ de Maceió.

O solo foi caracterizado como Latossolo Vermelho Amarelo distrófico, de acordo com a classificação da EMBRAPA (2006) com declividade de 0,05. Os resultados da análise química do solo se encontram na Tabela 1.

Segundo a classificação de Köppen, o clima da região foi classificado como As, ou seja, climático tropical com estação chuvosa no inverno e seca no verão. A temperatura, a precipitação pluviométrica e a evapotranspiração na região durante o período correspondente ao desenvolvimento do experimento, são indicadas na Figura 1.

O delineamento estatístico utilizado foi blocos casualizados dispostos em fatorial 3 x 3 com quatro repetições, cujos fatores são três fontes de silício (cinza do bagaço da cana-de-açúcar, MB-4 e Rocksil $\left.{ }^{\circledR}\right)$ e três doses de cada fonte $\left(0 \mathrm{~kg} \mathrm{ha}^{-1}, 400 \mathrm{~kg} \mathrm{ha}^{-1}\right.$ e $\left.800 \mathrm{~kg} \mathrm{ha}^{-1} \mathrm{de} \mathrm{SiO}_{2}\right)$ divididas em quatro aplicações. Cada parcela, com uma touceira e várias brotações, ocupava uma área útil de $1 \mathrm{~m}^{2}$; as principais características químicas de cada fonte de silício utilizada são apresentadas na Tabela 2.

A partir da Tabela 2 observa-se que o teor de $\mathrm{SiO}_{2}$ e dos demais nutrientes é bastante variável entre as fontes, com destaque para enxofre, no Rocksil ${ }^{\circledR}$, cálcio e ferro no MB-4 e ferro e fósforo na cinza.

As mudas foram provenientes de touceiras de plantas adultas de helicônia "Golden Torch", compostas de rizomas com pedaços de 10 a $12 \mathrm{~cm}$ de pseudocaule. Todo o material foi submetido a uma limpeza para remoção de solo e raízes, tratadas com uma solução contendo $1 \%$ de fungicida cúprico (Manzate ${ }^{\circledR}$ ) antes do plantio.

No plantio foi utilizada uma mistura de adubo orgânico + mineral, cuja fonte foi esterco de gado $\left(12 \mathrm{~L} \mathrm{~m}^{-2}\right)+$ NPK (05-15-05) na dose de $200 \mathrm{~g} \mathrm{~m}^{-2}$, para fundação. A cada três meses após a realização do plantio foram feitas as adubações de cobertura com uma mistura de adubo orgânico + mineral, tendo como fonte o esterco de gado na dose de $12 \mathrm{~L} \mathrm{~m}^{-2} \mathrm{e}$ NPK (12-04-12) na dose de $200 \mathrm{~g} \mathrm{~m}^{-2}$. As fontes de NPK para elaboração da fórmula acima, foram ureia, superfosfato simples e cloreto de potássio. Os tratamentos com silício foram aplicados em quatro etapas: um quarto na fundação

Tabela 1. Análise química de solo na profundidade 0-0,20 m antes da instalação do cultivo de helicônia "Golden Torch"

\begin{tabular}{|c|c|c|c|c|c|c|c|c|c|c|c|c|c|c|}
\hline $\mathrm{pH}$ & $\mathrm{Na}$ & $\mathbf{P}$ & $\mathrm{Fe}$ & $\mathrm{Cu}$ & $2 n$ & $\mathrm{Mn}$ & & $\bar{K}$ & $\mathrm{Ca}$ & $\mathrm{Mg}$ & $\mathrm{Al}$ & $\mathrm{H}+\mathrm{Al}$ & $\begin{array}{l}\text { CTC } \\
\end{array}$ & \multirow{2}{*}{$\begin{array}{c}\mathbf{V} \\
\% \\
88,6\end{array}$} \\
\hline $\begin{array}{c}\text { (água) } \\
6,5\end{array}$ & \multicolumn{6}{|c|}{$\mathrm{mg} \mathrm{dm}^{-3}$} & $\begin{array}{c}\left(\mathbf{g ~ k g}^{-1}\right) \\
3,2\end{array}$ & 0,42 & 8,1 & $\begin{array}{r}\mathbf{c} \\
1,6\end{array}$ & $\begin{array}{c}{ }_{c} \mathbf{d m} \\
0,4\end{array}$ & 1,3 & 11,42 & \\
\hline
\end{tabular}




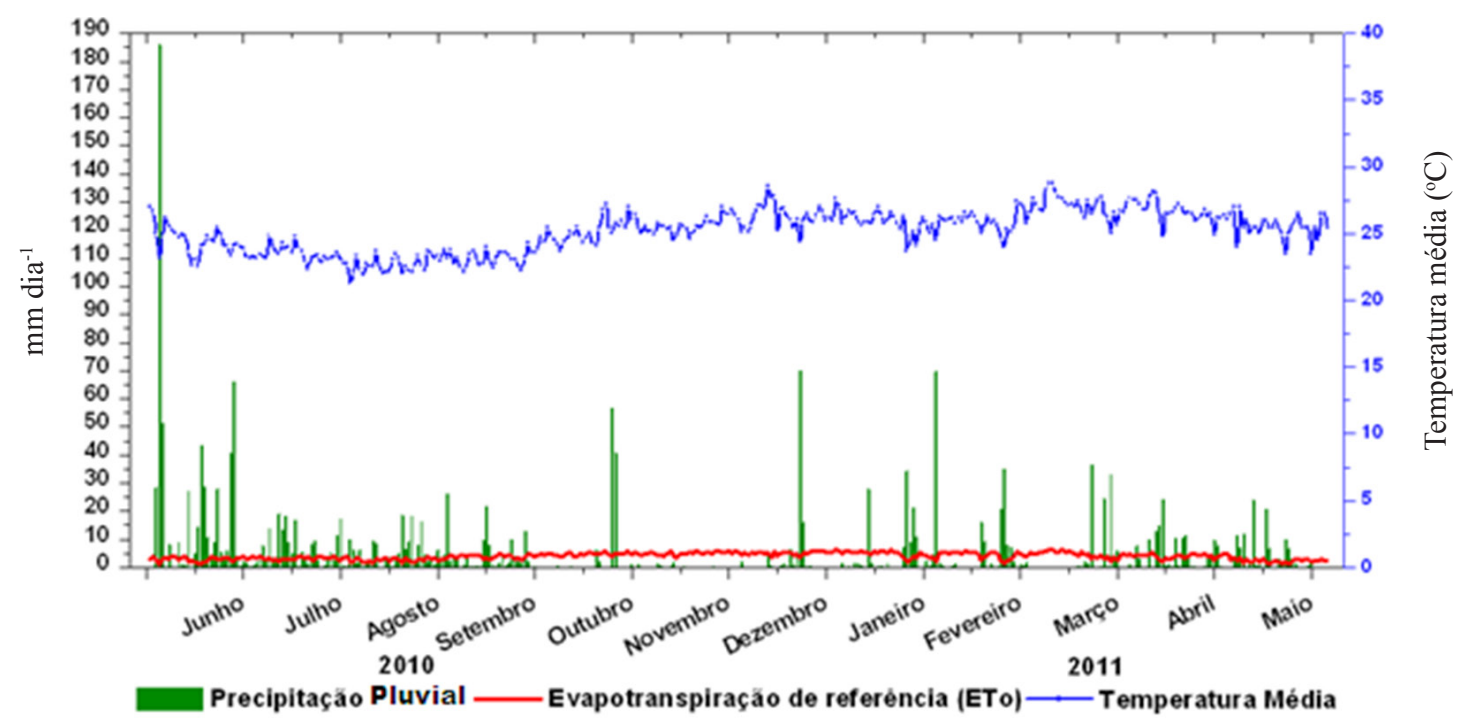

Figura 1. Dados climáticos de temperatura média, precipitação e evapotranspiração de referência no período de junho de 2010 a maio de 2011

Tabela 2. Análise química das fontes de silício utilizadas no experimento

\begin{tabular}{|c|c|c|c|c|c|c|c|c|}
\hline Fontes & $\mathrm{SiO}_{2}$ & $S$ & $\mathrm{CaO}$ & $\mathrm{MgO}$ & $\mathrm{Fe}_{2} \mathrm{O}_{3}$ & $\mathrm{P}_{2} \mathrm{O}_{5}$ & $\mathrm{Al}_{2} \mathrm{O}_{3}$ & $\mathrm{~K}_{2} \mathrm{O}$ \\
\hline Fontes & \multicolumn{8}{|c|}{$\mathrm{mg} \mathrm{kg}^{-1}$} \\
\hline MB-4 & 170 & 1,8 & 59,0 & 0,74 & 69,0 & 0,75 & 71 & 8 \\
\hline Rocksil $\circledast$ & 174 & 98,0 & 13,0 & 1,80 & 1,6 & 1,00 & 206 & . \\
\hline Cinza & 550 & - & 9,6 & 0,80 & 61,0 & 4,00 & - & 7 \\
\hline
\end{tabular}

Fonte: Santos (2011)

e os outros três quartos foram divididos em três partes e aplicados junto à adubação de cobertura. Em seu total, a adubação de cobertura foi realizada a lanço, ao redor da planta, sem incorporação.

Quando da avaliação do experimento não foi constatada a presença de agentes patogênicos com potencial para causar prejuízos ao desenvolvimento nem à condução da cultura. $\mathrm{O}$ controle de plantas invasoras foi realizado com capina manual helicônia, sempre que necessário. Realizaramse também, nos meses de abril e maio, pulverizações de caldas com $1 \%$ de extrato de nim comercial para controle de Cornops frenatum, que se alimenta das folhas, de acordo com Lemos et al. (2006).

Com vista à manutenção da umidade do solo utilizou-se o sistema de irrigação por microaspersão com modelo Supernet LR 40, autocompensante e vazão de $40 \mathrm{~L} \mathrm{~h}^{-1}$, distribuídos sob espaçamento de 4,0 m nas linhas e 3,0 m nas entrelinhas, acionado até duas vezes ao dia durante $45 \mathrm{~min}$ proporcionando, a cada vez, uma lâmina mínima de $5,0 \mathrm{~mm} \mathrm{~d}^{-1}$.

As amostras para avaliação dos tratamentos foram coletadas nos meses de janeiro a maio de 2011; após a última aplicação das fontes de silício, em setembro de 2010, ocorreram duas coletas semanais das inflorescências quando atingiam o ponto de colheita com duas a três brácteas abertas. As amostras eram identificadas, acomodadas em baldes contendo água e levadas para um galpão de armazenamento arejado com temperatura ambiente entre 22 e $29^{\circ} \mathrm{C}$ para em seguida se fazer as medições.

As variáveis utilizadas para avaliar os tratamentos quanto à produtividade, foram:

Número de hastes florais por metro quadrado (NHF): obtido a partir da contagem das inflorescências comercializáveis, colhidas no período de avaliação, ou seja, janeiro a maio de 2011.

Comprimento de hastes florais $(\mathrm{CHF}, \mathrm{cm})$ : medido com utilização de uma fita métrica; para a aferição do CHF a haste floral era colhida a $10 \mathrm{~cm}$ do solo e do ponto do corte até o ápice da inflorescência, era obtido seu valor.

Comprimento de bráctea $(\mathrm{CB}, \mathrm{cm})$ : obtido a partir da base de inserção da inflorescência até o limite da primeira bráctea, com uso de uma fita métrica.

As principais variáveis utilizadas para avaliar os tratamentos quanto à qualidade pós-colheita, foram:

Massa de hastes florais (MHF, g) e massa de hastes florais no oitavo dia pós-colheita (MHFPC, g): foram medidas com a utilização de uma balança digital da marca Filizola modelo F-400 com precisão de $0,01 \mathrm{~g}$. A MHF foi medida a partir de pesagem no ato da colheita e a MHFPC foi aferida oito dias após a colheita para o que as hastes foram acomodadas em baldes com água e colocadas no galpão de armazenamento.

Perda de massa de hastes florais no oitavo dia póscolheita (PMO, \%): obtida a partir da diferença da massa das inflorescências, no ato da colheita e oito dias após a colheita.

Queima de bráctea no oitavo dia pós-colheita (QBO, \%): medida com a utilização de uma fita métrica para aferir as dimensões das brácteas (primeira bráctea de cada inflorescência) no ato da colheita e as dimensões queimadas (ressecadas) após o oitavo dia da colheita. As dimensões queimadas foram obtidas pela subtração entre os valores aferidos no ato da colheita e a parte não queimada, ao oitavo dia. Com as dimensões foram calculadas as áreas aproximadas das brácteas, pelas seguintes Eqs. 1, 2 e 3 (Santos, 2006). 


$$
\mathrm{A}=\frac{[(\mathrm{B}+\mathrm{b}) \mathrm{C}+3 \mathrm{CB}]}{4}
$$

em que:

A - área da bráctea no ato da colheita, ${\mathrm{em} \mathrm{cm}^{2}}^{2}$

B - largura máxima da bráctea, em $\mathrm{cm}$

b - largura da base da bráctea, em $\mathrm{cm}$

C - comprimento total da bráctea, em $\mathrm{cm}$

$$
\mathrm{Aq}=\mathrm{Lc}
$$

em que:

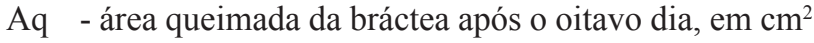

L - largura máxima da área queimada, $\mathrm{cm}$

C - comprimento da parte queimada da bráctea

$$
\mathrm{QBO}=\left(\frac{\mathrm{Aq}}{\mathrm{A}}\right) 100
$$

em que:

QBO - queima da bráctea ao oitavo dia, \%

A - área da bráctea no ato da colheita, em $\mathrm{cm}^{2}$

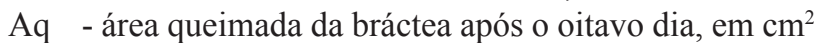

Teor de silício foliar (TSF, $\mathrm{g} \mathrm{kg}^{-1}$ ): foi feito no Laboratório de Fertilidade de Solos do Instituto de Ciências Agrárias da Universidade Federal de Uberlândia (LAFER/ICIAG/UFU) de acordo com o método da EMBRAPA (1999). Para TSF, foi retirado o terço médio da primeira folha totalmente expandida a partir da inflorescência de todas as que estavam abertas no ato da colheita; logo após, o material foi secado em estufa a 65 ${ }^{\circ} \mathrm{C}$, por $48 \mathrm{~h}$ e triturado.

Teor de silício no solo nas profundidades de 0-0,20 (TSS20) e $0,20-0,40$ m (TSS-40): para determinação do TSS-20 e do TSS-40, foram coletadas amostras simples de solo em três pontos de cada parcela nas profundidades de $0-20$ e $20-40 \mathrm{~cm}$ de cada parcela as quais, homogeneizadas, formaram a amostra composta e foram secadas em estufa a $105^{\circ} \mathrm{C}$, por $24 \mathrm{~h}$; após a secagem as amostras de solo foram enviadas ao LAFER/ICIAG/UFU para análise, que o método descrito pela EMBRAPA (1999).

Todos os dados obtidos para avaliação dos tratamentos foram submetidos à análise de variância com o programa
SAEG (1995); em seguida, aplicou-se o teste de agrupamento de médias de Scott-Knotttal como, também o teste de média a $5 \%$ de probabilidade para fontes enquanto para os dados referentes às doses foi aplicada análise de regressão. Obtido o nível de significância das variáveis estudadas foram determinadas as equações de regressão e determinada sua significância estatística, identificando-se as que melhor se ajustaram em função das doses aplicadas de $\mathrm{SiO}_{2}$ em suas respectivas fontes.

\section{Resultados E Discussão}

A análise de variância dos dados obtidos está na Tabela 3 podendo-se observar que ocorreu significância para o fator fontes, correspondente às variáveis NHF, PMO e QBO e que, para o fator doses, foi constatada significância para as variáveis TSS-20 $(0,01)$, QBO $(0,05)$ e TSS-40 $(0,05)$. Com relação à interação fontes $\mathrm{x}$ doses, foi constatada significância a nível de 0,05 da probabilidade para as variáveis $\mathrm{CB}, \mathrm{PMO}$, QBO e TSS-40.

Em relação ao número de hastes florais por metro quadrado (NHF), a fonte Rocksil ${ }^{\circledR}$ foi estatisticamente superior às demais, fato passível de ter ocorrido devido à maior solubilidade do Rocksil $^{\circledR}$ em relação à cinza e ao MB-4 conforme relatado por Pereira et al. (2007). Os valores obtidos corroboram com Santos (2006) que encontrou relação entre solubilidade das fontes de Si e NHF em "Golden Torch".

Os maiores teores de enxofre e magnésio do Rocksil ${ }^{\mathbb{R}}$ (Tabela 2) também podem ter contribuído para NHF visto que esses nutrientes estão associados à emissão de ramos e inflorescências mais numerosos e uniformes.

O NHF é uma variável bastante apreciada pelos produtores, de vez que maior número de flores representa mais produtos comercializáveis. Na Tabela 4 observa-se que o NHF variou entre 46,5 e 51,0 unidades colhidas no período de avaliação (janeiro a maio de 2011), ou seja, 9,3 a 10,2 hastes mês ${ }^{1}$ valores esses similares aos de Albuquerque et al. (2010) que colheram de 120,3 a 126,5 hastes florais $\mathrm{m}^{-2}$ utilizando adubação organomineral em cultivo de "Golden Torch" no município de Satuba, AL, em doze meses de avaliação (10 a 10,5 hastes mês ${ }^{-1}$.

Tabela 3. Resumo de análise de variância para as variáveis: número de hastes florais por metro quadrado (NHF), comprimento de hastes florais (CHF), comprimento de bráctea (CB), massa de haste floral (MHF), massa de haste floral ao oitavo dia pós-colheita (MHFPC), perda de massa da haste floral ao oitavo dia pós-colheita (PMO) e queima de bráctea ao oitavo dia pós-colheita (QBO), teor de silício foliar (TSF), teor de silício no solo na profun-

\begin{tabular}{|c|c|c|c|c|c|c|c|c|c|c|c|}
\hline \multirow[b]{2}{*}{ FV } & \multicolumn{11}{|c|}{ Quadro de análise de variância } \\
\hline & GL & \multicolumn{10}{|c|}{ Quadrado médio } \\
\hline Blocos & 3 & $0,89 \mathrm{~ns}$ & 107,43 ns & $4,28^{\star \star}$ & $89,59 \mathrm{~ns}$ & $82,12 \mathrm{~ns}$ & 0,02 ns & $1,32 \mathrm{~ns}$ & $0,01 \mathrm{~ns}$ & $0,27 \mathrm{~ns}$ & $0,10 \mathrm{~ns}$ \\
\hline Doses & 2 & $1,03 \mathrm{~ns}$ & $7,97 \mathrm{~ns}$ & $1,22 \mathrm{~ns}$ & $136,90 \mathrm{~ns}$ & $119,07 \mathrm{~ns}$ & 0,06 ns & $3,14^{*}$ & $0,03 n s$ & $2,30^{\star *}$ & $0,62^{*}$ \\
\hline$F \times D$ & 4 & $2,86 \mathrm{~ns}$ & 8,94 ns & $1,80^{*}$ & $75,60 \mathrm{~ns}$ & $66,63 \mathrm{~ns}$ & $0,09^{\star}$ & $1,77^{*}$ & $0,02 \mathrm{~ns}$ & $0,78 \mathrm{~ns}$ & $0,51^{*}$ \\
\hline Resíduo & 24 & 4,54 & 49,00 & 0,51 & 144,27 & 128,74 & 0,03 & 0,60 & 0,03 & 0,91 & 0,18 \\
\hline
\end{tabular}
didade de 0-20 cm (TSS-20) e de 20-40 cm (TSS-40) de helicônia "Golden Torch" cultivada sob diferentes fontes e doses de silício

** Significativo a 0,01 de probabilidade, * Significativo a 0,05 de probabilidade e ns- não significativo 
Tabela 4. Número de hastes florais por metro quadrado de helicônia "Golden Torch" cultivada sob diferentes fontes e dose de silício

\begin{tabular}{lcccc}
\hline \multirow{2}{*}{ Fontes } & \multicolumn{3}{c}{ Doses de $\mathbf{S i O}_{2}\left(\mathbf{k g ~ h a}^{-1}\right)$} & \multirow{2}{*}{ Médias } \\
\cline { 2 - 4 } & $\mathbf{0}$ & $\mathbf{4 0 0}$ & $\mathbf{8 0 0}$ & \\
Cinza & 46,75 & 47,25 & 48,00 & $47,33 \mathrm{~b}$ \\
MB-4 & 47,75 & 46,50 & 48,00 & $47,42 \mathrm{~b}$ \\
Rocksi ${ }^{\circledR}$ & 49,50 & 51,00 & 49,75 & $50,08 \mathrm{a}$ \\
\hline Médias & 48,00 & 48,25 & 48,58 & \\
\hline
\end{tabular}

Médias seguidas da mesma letra na coluna não diferem entre si pelo teste de Scott-Knott a nivel de 0,05 de probabilidade

Os valores de CHF oscilaram entre 78,28 e $84,74 \mathrm{~cm}$ e não se constatou diferença. O CHF em flores tropicais pode afetar diretamente a qualidade e o valor final do produto pois com inflorescências maiores é possível fazer arranjos mais robustos com um número menor de hastes (Arruda et al., 2008). Contudo, Cerqueira et al. (2008) e Souza et al. (2009) utilizando adubação semelhante e diferentes fontes de calcário encontraram comprimentos similares de hastes florais em "Golden Torch" mas não constataram diferenças no CHF. Os autores relatam que a baixa disponibilidade de nutrientes das fontes de silício utilizadas pode ter sido preponderante para que não houvesse diferença.

Com médias variando entre 17,11 e 18,93 cm (Tabela 5) os valores de comprimento bráctea (CB) estão de acordo com Albuquerque et al. (2010). Pelo teste de médias a fonte

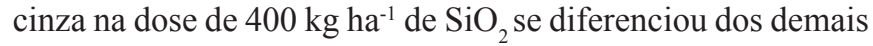
tratamentos apresentando um CB maior. Santos (2006) encontrou diferença entre fontes e doses de $\mathrm{Si}$ mas, para o autor, em doses intermediárias (400 a $800 \mathrm{~kg} \mathrm{ha}^{-1}$ ) o CB foi igual ou superior às doses máximas $\left(1200 \mathrm{~kg} \mathrm{ha}^{-1}\right)$.

Tabela 5. Comprimento de bráctea $(\mathrm{cm})$ de helicônia "Golden Torch" cultivada sob diferentes fontes e dose de silício

\begin{tabular}{lcccc}
\hline \multirow{2}{*}{ Fontes } & \multicolumn{3}{c}{ Doses de $\mathbf{S i O}_{2}\left(\mathbf{k g ~ h a}^{-1}\right)$} & \\
\cline { 2 - 4 } & $\mathbf{0}$ & $\mathbf{4 0 0}$ & $\mathbf{8 0 0}$ & \multirow{2}{*}{ Médias } \\
\cline { 2 - 4 } Cinza & \multicolumn{5}{c}{$\mathbf{( \mathbf { c m } )}$} & \\
MB-4 & $17,11 \mathrm{a}$ & $18,93 \mathrm{a}$ & $17,95 \mathrm{a}$ & 17,99 \\
Rocksil $^{\circledR}$ & $18,11 \mathrm{a}$ & $17,35 \mathrm{~b}$ & $17,83 \mathrm{a}$ & 17,76 \\
\hline Médias & $17,13 \mathrm{a}$ & $17,30 \mathrm{~b}$ & $17,66 \mathrm{a}$ & 17,36 \\
\hline
\end{tabular}

Médias seguidas da mesma letra na coluna não diferem entre si pelo teste de Scott-Knott a nível de 0,05 de probabilidade

O maior teor de fósforo na cinza também pode ter contribuído para que apresentasse médias superiores considerando-se que o $\mathrm{P}$ é um dos principais nutrientes para a formação e crescimento das inflorescências; mesmo assim, a dose de $800 \mathrm{~kg} \mathrm{ha}^{-1}$ pode ter ultrapassado a necessidade da cultura considerando-se que a adubação organomineral e o próprio solo fornecem $\mathrm{P}$, causando desequilíbrio nutricional.

Massa de hastes florais (MHF) e Massa de hastes florais no oitavo dia pós-colheita (MHFPC): a variável MHF com valores entre 84,05 e 96,86 g não apresentou diferença. Korndörfer et al.(2000) não constataram ligação direta entre a aplicação de Si e o acúmulo de massa em hortaliças; os autores relatam que a produção de massa está mais intimamente ligada a uma adubação organomineral equilibrada, ou seja, aos valores entre
79,02 e 91,17 g de MHFPC; ela é dependente, portanto, do valor de MHF, com base no fato de, não tendo sido encontrada diferença estatística para MHF, isto culmina em resultado semelhante para MHFPC.

Perda de massa de hastes florais no oitavo dia pós-colheita (PMO) apresentou médias de 4,58 e de 5,88\% (Tabela 6) para os tratamentos cinza $800 \mathrm{~kg} \mathrm{ha}^{-1} \mathrm{de}^{\mathrm{SiO}}$ e cinza sem $\mathrm{SiO}_{2}$, respectivamente, ou seja, uma diferença de $28,38 \%$. Esses valores estão de acordo com Souza et al. (2009) que encontraram valores similares em seus experimentos de qualidade pós-colheita com Heliconia spp. Independentemente das fontes, a dose $800 \mathrm{~kg} \mathrm{ha}^{-1}$ apresentou menor PMO quando comparada com os tratamentos sem silício.

Tabela 6. Perda de massa ao oitavo dia pós-colheita de helicônia "Golden Torch" sob diferentes fontes e dose de silício

\begin{tabular}{|c|c|c|c|c|}
\hline \multirow{3}{*}{ Fontes } & \multicolumn{3}{|c|}{ Doses de $\mathrm{SiO}_{2}\left(\mathrm{~kg} \mathrm{ha}^{-1}\right)$} & \multirow{3}{*}{ Médias } \\
\hline & 0 & 400 & 800 & \\
\hline & \multicolumn{3}{|c|}{$(\%)$} & \\
\hline Cinza & $5,88 \mathrm{a}$ & $5,36 \mathrm{a}$ & $4,58 \mathrm{a}$ & 5,27 \\
\hline MB-4 & $5,62 \mathrm{a}$ & $5,25 \mathrm{a}$ & $4,64 \mathrm{a}$ & 5,17 \\
\hline Rocksil $^{(\mathbb{R}}$ & $5,73 \mathrm{a}$ & $4,98 \mathrm{~b}$ & $4,71 \mathrm{a}$ & 5,14 \\
\hline Médias & 5,74 & 5,20 & 4,64 & \\
\hline
\end{tabular}

Médias seguidas da mesma letra na coluna não diferem entre si pelo teste de Scott-Knott a nível de 0,05 de probabilidade

Com relação à dose de $400 \mathrm{~kg} \mathrm{ha}^{-1}$ constatou-se que a fonte Rocksil ${ }^{\circledR}$ foi a que apresentou a menor PMO. Guimarães et al. (2010) relataram o mesmo comportamento quando da utilização de fatores que diminuem o estresse pós-colheita em Heliconia spp, implicando em um aproveitamento melhor das flores, por parte dos produtores.

A perda de massa fresca se dá principalmente pela desidratação ou transpiração considerando que o Si fica depositado na epiderme dos tecidos vegetais minimizando, assim, a saída da água. O aumento das doses de $\mathrm{SiO}_{2}$ (Tabela 6 ) pode propiciar uma perda menor de massa em relação aos tratamentos sem silício (Feitosa et al., 2010; Guimarães et al., 2010).

O aumento da dose de silício diminui a PMO colaborando para manutenção da massa fresca elevando, em consequência, a qualidade pós-colheita das inflorescências representando, desta forma, para os produtores e comerciantes, a possibilidade de atingir mercados cada vez mais longínquos. Para Brackmann et al. (2008), Souza et al. (2009) e Guimarães et al. (2010) o uso de técnicas e produtos que alterem a velocidade de transpiração diminui a PMO.

Referente aos dados obtidos para queima de bráctea no oitavo dia pós-colheita (QBO), não houve diferença estatística significativa para as doses 0 e $400 \mathrm{~kg} \mathrm{ha}^{-1} \mathrm{de} \mathrm{SiO}_{2}$ concernentes às fontes cinza, MB-4 e Rocksil ${ }^{\mathbb{B}}$ (Tabela 7). A combinação de fontes e a dose $800 \mathrm{~kg} \mathrm{ha}^{-1}$ de $\mathrm{SiO}_{2}$ apresentou diferença significativa sendo que Rocksil ${ }^{\circledR}$ apresentou o menor valor $(17,64 \%)$ diferindo estatisticamente de MB-4 e cinza.

A queima da bráctea é um processo natural que ocorre com o amadurecimento, desidratação e a senescência da inflorescência. A senescência é desencadeada sobremaneira pela síntese do etileno (Sonego \& Brackmann, 1995). Assim, 
Tabela 7. Queima de bráctea no oitavo dia pós-colheita de helicônia "Golden Torch" sob diferentes fontes e dose de silício

\begin{tabular}{|c|c|c|c|c|}
\hline \multirow{3}{*}{ Fontes } & \multicolumn{3}{|c|}{ Doses de $\mathrm{SiO}_{2}\left(\mathrm{~kg} \mathrm{ha}^{-1}\right)$} & \multirow{3}{*}{ Médias } \\
\hline & 0 & 400 & 800 & \\
\hline & \multicolumn{3}{|c|}{$(\%)$} & \\
\hline Cinza & $22,71 \mathrm{a}$ & $20,31 \mathrm{a}$ & $19,26 a$ & 20,76 \\
\hline MB-4 & $22,61 \mathrm{a}$ & $20,81 \mathrm{a}$ & $20,09 a$ & 21,17 \\
\hline Rocksil $^{\circledR}$ & $22,29 \mathrm{a}$ & $20,54 \mathrm{a}$ & $17,64 \mathrm{~b}$ & $20,15 \mathrm{~b}$ \\
\hline Médias & 22,54 & 20,55 & 19,00 & \\
\hline
\end{tabular}

Médias seguidas da mesma letra na coluna não diferem entre si pelo teste de Scott-Knott a nível de 0,05 de probabilidade

a presença do Si diminui a perda de água dentre outros fatores estressantes que favorecem a produção de etileno (Brackmann et al., 2008); segundo Feitosa et al. (2010) pode-se afirmar que o silício contribui para manutenção da qualidade das flores desfavorecendo sua degradação.

A partir da Figura 2 é possível observar que a queima de bráctea decresceu de forma linear com o aumento da dose de $\mathrm{Si}$, com destaque para a fonte Rocksil ${ }^{\circledR}$. Constata-se que as equações de regressão para cinza, MB-4 e Rocksil ${ }^{\circledR}$ na dose $800 \mathrm{~kg} \mathrm{ha}^{-1}$ de $\mathrm{SiO}_{2}$ apresentaram valores de 19,87; 19,05 e $17,84 \%$, respectivamente.

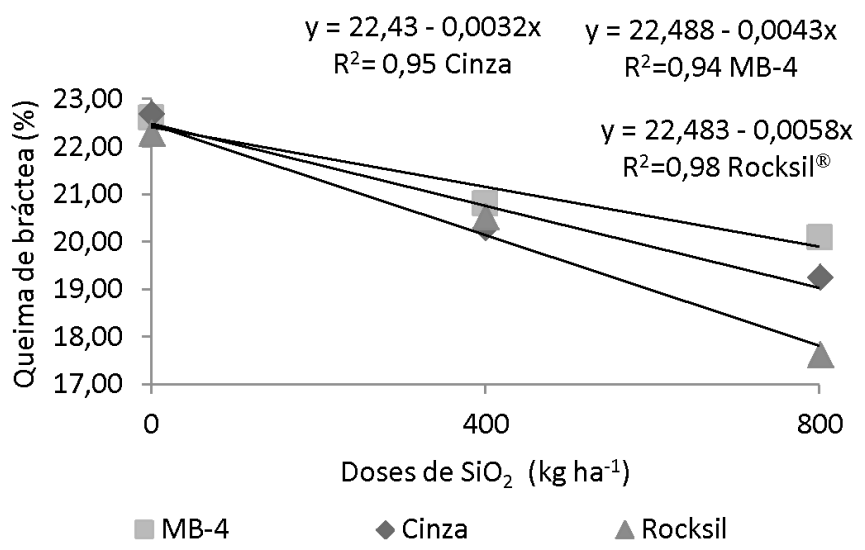

Figura 2. Relação entre queima de bráctea dose de $\mathrm{SiO}_{2}$ e queima de bráctea no oitavo dia pós-colheita

Conforme Santos (2006) o uso de silicato de sódio e silicato de potássio em helicônia Golden Torch diminuiu a queima de bráctea com o aumento da dose dos silicatos; para o autor, a absorção e a deposição da sílica principalmente na parede celular das brácteas deixam-nas mais rígidas e túrgidas, contrapondo-se à sua desnaturação.

O teor de silício foliar (TSF) com dados entre 6,7 e 9,2 $\mathrm{g} \mathrm{kg}^{-1}$ de silício não apresentou diferença estatística e ficou acima dos valores encontrados por Santos (2006) em "Golden Torch" 0,9 a 2,1 $\mathrm{g} \mathrm{kg}^{-1}$ e abaixo do intervalo, em musáceas 9,5 a 10,7 $\mathrm{g} \mathrm{kg}^{-1}$. Para o autor, mesmo sendo as helicônias acumuladoras de silício, as baixas doses utilizadas não foram suficientes para diferir dos tratamentos sem $\mathrm{Si}$, uma vez que o próprio solo é uma fonte deste elemento.

O teor de silício no solo (TSS-20) apresentou significância apenas para doses; na Figura 3 é possível notar que, com o crescimento da dose de $\mathrm{Si}$, seu teor no solo aumentou de maneira linear para todas as fontes. A equação de regressão estima que o teor máximo de silício no solo foi de 3,0 mg $\mathrm{kg}^{-1}$; Pereira et al. (2007) ressalta que, sendo este elemento de pouca mobilidade no solo, nas doses aplicadas ele resulta em maiores teores na camada de aplicação; enfim, o TSS20 obtido variou de 2,3 e $3,6 \mathrm{mg} \mathrm{kg}^{-1}$ corroborando com os autores, para Si no solo.

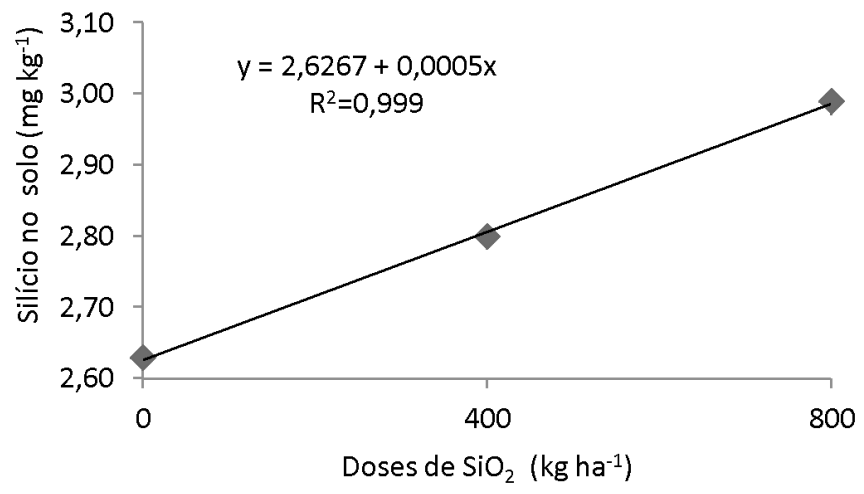

Figura 3. Relação entre doses de $\mathrm{SiO}_{2}$ e quantidade de silício no solo profundidade de $0-20 \mathrm{~cm}$

Em relação ao teor de silício na profundidade de 0,20-0,40 $\mathrm{m}$ (TSS-40), o teste de média não apontou diferença estatística para interação fontes e doses. Os dados da variável TSS-40 com valores entre 1,83 e 2,96 mg kg-1 corroboram com Korndörfer et al. (2000) e Pereira et al.(2007).

\section{Conclusões}

1. A adubação com silício aumenta a produção e diminui a deterioração das inflorescências.

2. A fonte de silício Rocksil ${ }^{\circledR}$ é superior às demais contribuindo para o aumento de produtividade e para a qualidade pós-colheita.

3. $\mathrm{O}$ aumento das doses de $\mathrm{SiO}_{2}$ contribui para a manutenção da qualidade pós-colheita da helicônia "Golden Torch" possibilitando um período maior de consumo.

\section{Literatura Citada}

Albuquerque, A. W.; Rocha, E. S.; Costa, J. P. V. da; Farias, A. P.; Bastos, A. L. Produção de helicônia Golden Torch influenciada pela adubação mineral e orgânica. Revista Brasileira de Engenharia Agrícola e Ambiental, v.14, p.1052-1058, 2010.

Arruda, R.; Carvalho, V. T. de; Andrade, P. C. M.; Pinto, M. G. Helicônias como alternativa econômica para comunidades amazônicas. Acta Amazonica, v.38, p.611-616, 2008.

Brackmann, A.; Eisermann, A. C.; Weber, A.; Giehl, R. F. H.; Pavanello, E. P.; Both, V. Qualidade da maçã "Gala" armazenada em atmosfera controlada associada à absorção e ao controle da síntese e da ação do etileno. Ciência Rural, v.38, p.2151-2156, 2008.

Branglione, P.; Sampaio, A. C.; Fischer, I. H.; Almeida, A. M. de; Fumis, T. de F. Eficiência de argila silicatada no controle de Xanthomonas axonopodis pv. passiflorae in vitro e em mudas de maracujazeiro-amarelo. Revista Brasileira de Fruticultura, v.31, p.718-724, 2009. 
Buck, G. B.; Konrdörfer, G. H.; Nolla, A.; Coelho, L. Potassium silicate as foliar spray and rice blast control. Journal of Plant Nutrition, v.31, p.231-237, 2008.

Castro, A. C. R. de; Loges, V.; Costa, A. S. da; Castro, M. F. A. de; Aragão, F. A. S. de; Willadino, L. G. Hastes florais de helicônia sob deficiência de macronutrientes. Pesquisa Agropecuária Brasileira, v.42, p.1299-1306, 2007.

Cerqueira, L. L.; Fadigas, F. de S.; Pereira, F. A.; Gloaguen, T. V.; Costa, J. A. Desenvolvimento de Heliconia psittacorume Gladiolus hortulanus irrigados com águas residuárias tratadas. Revista Brasileira de Engenharia Agrícola e Ambiental, v.12, p.606-613, 2008.

Cordeiro, G. C.; Toledo Filho, R. D.; Fairbairn, E. de M. R. Caracterização de cinza do bagaço da cana-de-açúcar para emprego como pozolana em materiais cimentícios. Química Nova, v.32, p.82-86, 2009.

Costa, A. S. da; Loges, V.; Castro, A. C. R. de; Bezerra, G. J. S. de M.; Santos, V. F. dos. Variabilidade genética e correlações entre caracteres de cultivares e híbridos de Heliconia psittacorum. Revista Brasileira de Ciências Agrárias, v.2, p.187-192, 2007.

EMBRAPA - Empresa Brasileira de Pesquisa Agropecuária. Manual de análises químicas de solos, plantas e fertilizantes. Brasília: Embrapa Comunicação para Transferência de Tecnologia. 1999. 370p.

EMBRAPA - Empresa Brasileira de Pesquisa Agropecuária. Sistema brasileiro de classificação de solos. Recife: Embrapa Solos, 2006. 306p.

Feitosa, D. G.; Maltoni, K. L.; Silva, I. P. de F. Efeitos da adição de cinza da agroindústria no solo e no crescimento do milho, em cultivo protegido. Horticultura Brasileira, v.12, p.372-376, 2010.

Guimarães, A. A.; Finger, F. L.; Guimarães, A. A.; Souza, P. A. de; Linhares, P. C. F. Fisiologia pós-colheita de Heliconia spp. Revista Verde de Agroecologia e Desenvolvimento Sustentável, v.5, p.38-49, 2010.

Korndörfer, G. H.; Colombo, C. A.; Leone, P. L. C. Termofosfato como fonte de silício para cana-de-açúcar. Revista STAB, v.19, p.34-36, 2000.
Lemos, W. de P.; Ribeiro, R. C.; Souza, L. A. de. Cornops frenatum (Marschall) (Orthoptera: Acrididae): Principal desfolhador em cultivos de Heliconia spp. (Heliconiaceae) no Estado do Pará. Belém: Embrapa Amazônia Oriental, 2006. 4p. Comunicado Técnico, 164.

Oliveira, L. A. de; Korndörfer, G. H.; Pereira, A. N. Acumulação de silício em arroz em diferentes condições de $\mathrm{pH}$ da rizosfera. Revista Brasileira de Ciência do Solo, v.31, p.685-690, 2007.

Pereira, H. S.; Barbosa, N. C.; Carneiro, M. A. C.; Korndörfer, G. H. Avaliação de fontes e extratores de silício no solo. Pesquisa Agropecuária Brasileira, v.42, p.239-247, 2007.

Pereira, H. S.; Korndörfer, G. H.; Moura, W. F.; Corrêa, G. F. Extratores de silício disponível em escória e fertilizantes. Revista Brasileira de Ciência do Solo, v.27, p.265-274, 2003.

Ramos, L. A.; Korndörfer, G. H.; Nolla, A. Acúmulo de silício em plantas de arroz do ecossistema de várzea submetido à aplicação de diferentes fontes. Bragantia, v.67, p.751-757, 2008.

SAEG - Sistema de análises estatísticas e genéticas. Viçosa: UFV, 1995.

Santos, A. C. N. dos. Fontes de silício na adubação de mamoeiro 'Sunrise Solo': efeito sobre as características químicas do solo, o desenvolvimento das plantas e a qualidade dos frutos. Rio Largo: UFAL, 2011. 95p. Dissertação Mestrado

Santos, J. M. dos. Comportamento da heliconia Golden Torch (Heliconia psittacorumx spathorcircinada) submetida a fontes e doses de silício. Rio Largo: UFAL, 2006. 112p. Dissertação Mestrado

Sonego, G.; Brackmann, A. Conservação pós-colheita de flores. Ciência Rural, v.25, p.473-479, 1995.

Souza, G. O. de,; Viégas, I. de J. M.; Frazão, D. A. C. Crescimento de Heliconia psittacorum cv. Golden Torch em função de calcário dolomítico. Revista de Ciências Agrárias, v.52, p.49-59, 2009. 